Journal of Social Sciences 1 (4): 197-198, 2005

ISSN 1549-3652

(c) 2005 Science Publications

\title{
The Six Stages of the Healthcare Economy-Is Socialized Medicine at the Door? A Historical Review
}

\author{
Eldo E. Frezza \\ Division of General Surgery, Department of Surgery, Texas Tech University Health Science Center \\ Lubbock, Texas 79415
}

\begin{abstract}
The healthcare industry, nonexistent a century ago, is now a huge fraction of the U.S. economy and an intricate business with a multitude of legislative problems. This review article will summarize the recent history of the healthcare industry, evaluate how hospitals today make and lose money, and provide a few projections about the future of healthcare in America. The hope is that the healthcare industry will provide new incentives for physicians. A first step would be to improve prevention, which will decrease hospitalization. A second step would be to decrease the administrative workload involved in seeing patients so that physicians can see more of them without decreasing the quality of care provided. The growth in the number of elderly patients who require more and more sophisticated medical technology is an important demographic trend. This group's healthcare is government-funded; socialized medicine is inevitable if for no other reason than the needs of this group will soon be where most healthcare dollars are spent.
\end{abstract}

Key words: Quality of care, capitation payment, prospective payment, stages of healthcare revolution

\section{INTRODUCTION}

Evaluating healthcare's evolution is a difficult venture. The healthcare industry, nonexistent a century ago, is now a huge fraction of the U.S. economy and an intricate business with a multitude of legislative problems. Understanding how this behemoth arose from dealing with such issues as no insurance, to pay per case, and lastly to capitation, requires a historical context. This article reviews the recent history of the healthcare industry, dividing it into six parts, evaluates how hospitals today make and lose money, and provides a few projections about the future of healthcare in America. The article is based on the author's own knowledge of the subject as taught at the Master's level, since the book and references about this subject are scanty and confusing.

The first U.S. health insurance company: Concerned about patients who were not paying their hospital bills, Justin Ford Kimbalo, a member of the board of trustees at Baylor University in Texas, formed Blue Cross in the 1930's. Most hospitals were non-profit corporations run by charitable organizations, which Kimbalo thought deserved protection from financial risks. The payment method chosen was cost reimbursement.

The first health management organization (HMO): In an effort to build ships for the war effort in the 1940 's, Eric Kaiser offered employees health benefits to facilitate recruitment because wage controls precluded higher salaries. The basis of this first HMO was prospective payment or capitation. HMOs faced vigorous opposition for many years. The Oregon Medical Association persuaded the legislature to bar HMO's. Medical associations simultaneously excluded physicians who worked for HMO's from their membership and required local medical association membership for doctors who would obtain hospital privileges. In the 1980's, federal legislation abolished all such restrictions; HMO's that offered outstanding insurance then flourished across the country.

The six stages of healthcare revolution: Code Blue (1) divides healthcare's history into four stages, but this author believes six stages better delineate the complex changes in this industry.

First stage: The catchphrase of the 1950's was "if you build the hospitals, they will come." The care was determined by the availability of hospitals beds, whose construction the government funded. Power lay in the hands of the provider with the most assets. Fee-forservice dominated reimbursement, providing few incentives to control costs. Hospitals and insurance companies billed marketable profit, failing to use the more lucrative costs-plus contracts that formed the principle financial vehicles of Medicare and Medicaid.

Second stage: In the 1970's, hospital oversupply led to competition for market share. Built beds that once guaranteed profit now ensured failure unless they were

Corresponding Author:

Eldo Ermenegildo Frezza M.D., MBA, Chief of the Division of General Surgery, Department of Surgery, Texas Tech University Health Science Center, MOP Building, Suite 380, $35029^{\text {th }}$ Street, Lubbock, Texas 79415, Tel: 806-743-4666, Fax: 806-743-4670 
filled. Cost reimbursement, payment according to the length of stay, became normative, naturally yielding longer hospital stays. Most insurers assumed the role of intermediary, simply passing the added cost to employers, who then increased premiums charged employees. Rarely did insurance question the validity of provider charges. Therefore, cost reimbursement provided few incentives for cost control. Many began to believe that the best way to become more efficient was to design a simple reimbursement system, which soon came to fruition.

Third stage: The early 1980's gave birth to prospective payment, through which insurance companies negotiated a fixed price for a set of medical goods and services prior to the onset of the patients' illness. Prospective payment increased hospital and physician risks; to control these risks hospitals devised cost accounting. The most important innovation, Diagnosis Related Groups (DRG's), fixed payments to specific diagnoses, based upon diagnoses on discharge. This change dropped the average hospital stay from 13 to 7 days.

Fourth Stage: In the latter half of the 1980's downsizing eliminated unprofitable programs and duplicate facilities. Consolidation of hospitals into corporate chains proved a difficult transition for hospitals and administrators accustomed to autonomy and a relative lack of accountability.

Fifth stage: The hospital-driven HMO was born in the 1990's as a revenue source for the hospital. The genius of this "comprehensive" healthcare solution lay in a capitation that gave physicians a fixed amount per patient per month to provide specific services, irrespective of the needs of individual patients. The ostensible purpose was its incentive to make physicians concentrate on illness prevention, but all too often illness prevention was thinly-disguised fraud and undertreatment.

Hospital administrators now depended for their incomes upon less inpatient care; the critical change was that an empty bed became a profitable bed. This paradigm shift, beyond the comprehension of many administrators, caused some $30 \%$ to lose their jobs.

Sixth stage: Fraud and under-treatment, combined with a frontal assault against private insurance companies under the Clinton administration, led to concerns about quality.
Non-health care industry mottos, such as total quality management and continuous quality improvement, became insurance company mantras, soon to be repeated by hospitals and physicians eager to accrue insurance contracts. Conformance to "standard of care" comprised evaluation of medical records, both physician office and hospital, and, of course, the business office.

Current hospital profit and loss centers: Hospitals make money by aggressively contracting with HMO's, exerting such geographical leverage as anti-trust laws will permit, emphasizing prevention to both physicians and patients, limiting admissions, and expediting discharge with clinical pathways. Hospitals lose money through excessive admissions, excess lengths of stay, inpatient treatment of outpatient-treatable conditions, insufficient emphasis on preventive care, inattention to nosocomial infections, a lack of early outpatient care, premiums that do not cover costs and incomplete medical records that insufficiently document the need for care.

The hospitals' challenges: HMO's pre-certification effectively controls utilization and blocks some procedures, but also dictates patient care. The power of the HMO's has panicked the healthcare industry; physicians now see excess patients to increase revenue, since the payment for single patients is not as good as in the past. Hospitals, facing the same issues, fire employees and require increased work from those who remain; nurses who once cared for six or eight patients now bear the responsibility for a dozen. The system, unadjusted, will lower quality of care.

Is socialized medicine coming? The hope is that the healthcare industry will provide new incentives for physicians. A first step would be to improve prevention, which will decrease hospitalization. A second step would be to decrease the administrative workload involved in seeing patients, so physicians can see more without decreasing the quality of care. Neither step will address the underlying problem, the growth in the number of elderly patients who require more and more sophisticated medical technology that is becoming more readily available. This group's healthcare is government-funded; socialized medicine is inevitable if for no other reason than the needs of this group will soon be where most of the healthcare dollars are spent.

\section{REFERENCES}

1. Code Blue. 2002. Third Edition. McDermott RE, Stocks KD. Traemus Books. 